\title{
The multi-layered nature of the internet-based democratization of brand management 论
}

Bjoern Asmussen ${ }^{\mathrm{a}, *}$, Sally Harridge-March ${ }^{\mathrm{a}}$, Nicoletta Occhiocupo ${ }^{\mathrm{a}}$, Jillian Farquhar ${ }^{\mathrm{b}}$

${ }^{a}$ Department of Marketing, Business School, Oxford Brookes University, Wheatley Campus, Oxford, OX33 1HX, United Kingdom

${ }^{\mathrm{b}}$ Business and Management Research Institute, Business School, University of Bedfordshire, Luton, LU1 3JU, United Kingdom

The authors thank Lyndon Simkin, Yuksel Ekinci, the JBR special issue reviewers and special issue editors for their comments on earlier versions of this paper. The lead author would also like to acknowledge financial support from Oxford Brookes University.

* Corresponding author. Tel.: +44 1865485897.

Email addresses: bjoern.asmussen@brookes.ac.uk (B. Asmussen), occhipr@inwind.it (N. Occhiocupo), jillian.farquhar@beds.ac.uk (J. Farquhar) 


\begin{abstract}
The evolution of the internet, including developments such as Web 2.0, has led to new relationship realities between organizations and their stakeholders. One manifestation of these complex new realities has been the emergence of an internet-based democratization of brand management. Research about this phenomenon has so far mainly focused on investigating just one or more individual themes and thereby disregarded the inherent multilayered nature of the internet-based democratization of brand management as a holistic, socio-technological phenomenon. The aim of this paper is to address this limitation through an investigation of the various socio-technological democratization developments of the phenomenon. To achieve this aim, a balanced and stakeholder-oriented perspective on brand management has been adopted to conduct an integrative literature review. The review reveals three key developments, which together form the essential parts of the phenomenon: (I) the democratization of internet technology, (II) the democratization of information, and (III) the democratization of social capital. The insights gained help to clarify the basic structures of the multi-layered phenomenon. The findings contribute also to the substantiation of a call for a new brand management paradigm: one that takes not only company-initiated but also stakeholder-initiated brand management activities into account.
\end{abstract}

Keywords Brand, Branding, Brand management, Internet, Democratization, Stakeholder, Social capital 


\section{Introduction}

The evolution of the internet, including developments such as Web 2.0, has led to new relationship realities between organizations and their stakeholders. One manifestation of these complex new realities has been the emergence of an internet-based democratization of brand management. Research about this recent phenomenon has to date mainly focused on investigating just one or more individual themes, for example, internet-based user innovation, collective intelligence, electronic word-of-mouth or online communities (see Arnhold, 2010; Burmann and Arnhold, 2008). Minimal attention has been paid to the inherent multi-layered nature of the internet-based democratization of brand management as a holistic, sociotechnological phenomenon. The present paper aims to address this limitation by investigating the multi-layered nature of this phenomenon through an exploration of its various sociotechnological democratization developments.

When investigating the complex democratization processes researchers are confronted with the issue of conflicting conceptualizations. Tuten (2008), for example, defines brand democratization as "the invitation to consumers to participate in creating and then experiencing a brand's meaning" (p. 176). Not only is this definition limited to organizationconsumer relationships, and thereby neglecting relationships with other potentially relevant brand stakeholders, but it also implies that an organization has control over who it can invite to participate in the creation of a brand's meaning, which is not always the case. Plunkett (2011) conceptualizes the term brand democratization in a similar narrow, company-controlcentric way by defining it as a "practice of allowing" (p. ii) product fans and interested consumers to participate in brand-related activities. This, again, appears to exclude the possibility that some consumers (and other stakeholders) might participate in brand-related activities, without necessarily being invited by the allowing organization. In contrast to these two conceptualizations, Neisser (2006) emphasizes that consumers cannot be controlled, for 
instance, in their new roles as online critics or reviewers. He defines brand democratization as a development that puts consumers increasingly in control: through the internet, consumers are increasingly enabled to take charge and transform their relationships with brands "from ordinary buyer to reviewer, inventor, designer, ad creator, champion or critic" (p. 40). Nonetheless, Neisser's approach also seems too narrow by focusing just on consumers. All three authors disregard the importance of brand stakeholders other than consumers in their conceptualizations.

While these authors focus their considerations on the concept of brand democratization, others suggest more explicitly that not only brands but also branding, in the sense of brand management, is being democratized (Christodoulides, 2008 and 2009; Fournier and Avery, 2011; Hensel, 2008; Kemming and Humborg, 2010; Quelch and Jocz, 2007). Kemming and Humborg (2010), for example, conceptualize the democratization of branding as the "Technology-driven empowerment of consumers, such as the production of brand meaning by (micro) blogging, interaction in social networks or producing and disseminating brand advocacy" (p. 193). For Quelch and Jocz (2007), at least some of these internet-based processes have the potential to reduce or even circumvent the role of professional brand managers. Hensel (2008) acknowledges this as a "new era of brand management" by defining the key challenge for organizations now as finding a way to keep the balance between "guiding a brand and being guided as a brand" (p. 62).

Burmann and Arnhold (2008) offer their user generated branding approach as a response to this democratization challenge. Based on their research, they developed a managerial framework which conceptualizes user generated branding as "the strategic and operative management of brand related user generated content (UGC) to achieve [an organization's] brand goals" (p. 66). This approach allows the conceptual integration of stakeholders (i.e. users), instead of just consumers, and it also enables the conceptual integration of 
organization-initiated or organization-sponsored, brand-related UGC within a brand managerial context. But, due to its company-control-centric perspective, it falls short of enabling a conceptual integration of non-organization-initiated or non-sponsored, brandrelated UGC (beyond the realm of integrative social media monitoring; see Burmann and Arnhold, 2008). This appears to be a crucial conceptual limitation for the present democratization context, considering that what consumers and other stakeholders hear or read online about brands, in terms of genuine, non-sponsored UGC, is potentially far more important to them than any sponsored or otherwise organization-initiated, brand-related content (Christodoulides, 2008). To overcome this limitation a conceptualization of brand management seems to be needed that breaks free from an industrial age, company-controlcentric paradigm (Christodoulides, 2008 and 2009) and moves towards a more balanced (de Chernatony, 2001; Gummesson, 2002) and also more stakeholder-integrating (Merz et al., 2009; O’Guinn and Muniz, 2010) management perspective.

Such an outlook on brand management will be further discussed and conceptualized in the next section together with the need to adopt a socio-technological perspective on the internet-based democratization phenomenon as the point of departure for the present context. The aim of adopting this approach is to minimize the above mentioned issue of conflicting conceptualizations. The resultant definition is then used as a foundation for the investigation of the multi-layered nature of the internet-based democratization of brand management. The findings of this investigation are presented and discussed in the main section of the paper. Following the consideration of these results, the paper concludes with a discussion of the findings' wider implications but also limitations as well as potential future research directions. The paper's contribution is twofold. Firstly, it helps to clarify the basic structures of the multi-layered, socio-technological phenomenon consisting essentially of (I) the democratization of internet technology, (II) the democratization of information, and (III) the 
democratization of social capital. Secondly, it contributes to the substantiation of a call for a new brand management paradigm: one that takes not only company-initiated but also stakeholder-initiated brand management activities into account.

\section{Conceptualizing Brand Management and its Internet-based Democratization}

Brand management has been conceptualized from a variety of perspectives - most of them with an internal, external or balanced strategic orientation (Heding et al., 2009; Louro and Cunha, 2001). Since the purpose of this paper is to explore a relational phenomenon between organizations and their stakeholders, a balanced and stakeholder-integrating perspective has been chosen as the most appropriate brand management orientation. From such an angle, brands can be construed not only as company-controlled but also as socially constructed entities (Muñiz and O'Guinn, 2001), socio-cultural phenomena (Berthon et al., 2011), and/or complex social phenomena consisting of interrelated brand meanings, brand manifestations and internal as well as external brand stakeholders (Mühlbacher and Hemetsberger, 2008; Mühlbacher et al., 2006). Subsequently, the management of brands cannot be understood as consisting solely of organization-initiated or organization-sponsored processes. Rather, it needs to be understood as also entailing stakeholder-initiated activities that are not controlled by the organization.

Based on this societal perspective, brand management can be conceived as brand meaning management (Brown et al., 2003; McCracken, 2005), but compared to traditional views on meaning management, brand managers are not perceived as being able to manage brand meaning directly in their stakeholders' minds. They can only control - to a certain extent at least - the production of and access provision to certain brand manifestations, for instance, the manufacturing and distribution of products. The experience of these brand manifestations might then influence the stakeholders' creation, adjustment, or reinforcement of the brand 
meanings in their minds. Nonetheless, each person ultimately develops his or her own personal brand understanding based on various individual as well as socio-cultural factors. This rationale has led to the concept of brand meaning co-creation between an organization and its brand managers on one hand and its brand stakeholders on the other (Allen et al., 2008). Essential to the present argument though is the acknowledgement that, in the internet age, the power within this co-creation relationship has in many cases increasingly shifted away from organizations and brand managers towards their brand stakeholders. This is due to an unprecedented shift of resource availability regarding the creation of and access provision to brand manifestations.

In the pre-internet age, although word-of-mouth existed amongst consumers, organizations were generally considered the ones who set the brand meaning co-creation agenda (Berthon et al., 2009). Organizations constituted the main authors in the brand meaning co-creation process since they were seen as the providers of the major tangible and intangible brand manifestations, such as products and promotions. The consumers' role within the co-creation process was at this time usually limited to experiencing - and creating meaning out of - what the authors had to provide.

However, empowered by the internet, consumers and other stakeholders have now become potentially more active (co-)authors, agenda setters and access providers when it comes to brand manifestations. They are therefore able to contribute to the co-creation of brand meaning at a previously unreachable level since the internet, and related technologies, provide them with an unprecedented availability of resources to access, produce and/or distribute brand manifestations themselves; thus supporting the contention that consumers and other stakeholders - have "moved out of the audience and onto the stage" (Prahalad and Ramaswamy, 2000, p. 80). Beyond traditional word-of-mouth, they now have access to a broad variety of UGC platforms such as blogs and microblogs, social networking sites, wikis, 
and product review or video sharing sites. All these platforms potentially allow their users not only to enrich their own experience of a brand but also, for example, to express an opinion about it and therefore create a manifestation of the brand that can be experienced by others.

In this context, brand management can thus not only be conceptualized as brand meaning management but, more precisely, as brand manifestation management. This conceptualization entails (a) the creation of tangible as well as intangible brand manifestations; and (b) the control of access provision to these manifestations. The advantage of using such a conceptualization is that it allows researchers to move beyond traditional approaches towards an understanding of brand management as consisting of complex organizational as well as non-organizational processes that can potentially (i) not only involve consumers and employees but also other brand stakeholders; (ii) not only be co-creative and constructive but also co-destructive (Plé and Cáceres, 2010); (iii) be highly dynamic and fragmented; (iv) be directional as well as non-directional; (v) be dialogue-oriented as well as multilogue-oriented (Berthon et al., 2007); and (vi) include or exclude an organization and its brand managers from a multilogue amongst stakeholders about the organization's brand.

It also enables researchers to regard brand manifestations as brand touch points, brand experience points or brand meaning co-creation resources - no matter whether these have been created by an organization's internal or external brand stakeholders (see Burmann, 2010). Consequently, this brand management approach facilitates the full conceptual integration of non-organization-initiated or non-sponsored, brand-related UGC in a brand managerial context. Finally therefore, this conceptualization allows brand management researchers to shift the traditional comprehension that an organization is at the center of its brand's management to a viewpoint where it might instead be perceived as potentially just being one part of a complex brand management stakeholder network (Antorini and Schultz, 2005; Esmann Andersen and Nielsen, 2009; Post et al., 2002). 
This perspective also relates to the growing evidence in the literature that the traditional boundaries between an organization and its internal stakeholders on the one hand and its external stakeholders on the other, have become increasingly blurred (e.g. Gregory, 2007; Handelman, 2006; Pitt et al., 2006; Salzer-Mörling and Strannegård, 2004). For instance consumers, who are traditionally defined as external stakeholders, might as active members of an (online) brand community become endogenous to the firm and its brand management, for example, on a communications or new-product-development level (Schau et al., 2009). But, this does not necessarily mean that every internet-empowered brand stakeholder of a company now has to be considered as a (part-time) brand manager of that particular organization. Instead, organizations need to realize and internalize conceptually that brand management has quintessentially been democratized. The emergence and then evolution of the internet as a "democratizing change agent" (Kramer, 2008, p. 7) has led to a technologybased democratization of brand management in regards to the management of brand manifestations.

However, an exploration of these multi-layered democratization processes from a purely technological angle appears to be insufficient since the technological (infra-)structure of the internet cannot be separated from its use by social human actors and their permanent creation of meaningful information and communication through the internet (Fuchs, 2005). To be able to untangle the multi-layered nature of the internet-based democratization of brand management, the internet therefore needs to be interpreted as a socially embedded technology (Berners-Lee et al., 2006), since both society and technology are actively and continuously shaping each other (Halford et al., 2010). This approach takes into consideration that various internet technologies under investigation have only become powerful change agents through people's adoption and integration of these technologies in their everyday social lives (Anderson, 2007; Kelly, 2009). Consequently, this means that the technological as well as the 
societal developments need to be taken holistically into account - as two sides of the same coin. Thus a holistic, socio-technological perspective on the internet-based democratization phenomenon has been adopted as the point of departure for the present investigation.

The concept of democratization is in this context construed as a process of transition from a less to a more democratic form of power sharing (Grugel, 2002; Potter et al., 1997; Tilly, 2007). The internet-based democratization of brand management can subsequently be conceptualized as a phenomenon that occurs when the ability to use the internet leads to a more democratic form of power sharing between an organization and its brand stakeholders regarding the creation of and access provision to brand manifestations - compared to previous circumstances. The principle of power sharing implies hereby that power is a relational concept. To have more power as one part of a relationship means less power for the other(s); the power of an organization's stakeholders can therefore, to a certain extent at least, be related to the organization's power (Box, 1982).

This concept of relational power has been identified by Rezabakhsh et al. (2006) as consisting of various facets in the context of brand and marketing management. Building on French and Raven's (1959) framework of social power bases, Rezabakhsh et al. (2006) compared consumers' potential powers in the pre-internet age with those of the present times. They found that consumer power has increased on brand management-related bases such as reward and coercive power, expert power and legitimate power. These are exemplified in the following. Firstly, consumers' reward and coercive power has increased through their growing ability to voice their opinions about organizations and their brands on a potentially large scale, for example through blogs. Secondly, organizations' expert power has decreased through reductions in consumers' lack of information and increased market transparency, for instance through access to online product reviews. Thirdly, consumers' legitimate power to 
influence prices and products has been strengthened, for example through group-buying sites or websites that offer new levels of product personalization and specification.

However, the multi-layered nature of these various socio-technological power sharing and shifting processes has not yet been investigated in a brand managerial context. This paper therefore aims to contribute to the development of a deeper understanding regarding the multi-layered nature of the internet-based democratization of brand management. To achieve this aim, a broad integrative literature review has been conducted to explore the phenomenon's various socio-technological democratization developments. An integrative review was chosen as an appropriate research method since it is particularly suitable for the development of complex, holistic conceptualizations (Creswell, 2007; Torraco, 2005).

\section{Findings and Discussion}

The integrative literature review of the internet-based democratization of brand management identified three key developments that together form the essential parts of the phenomenon: (I) the democratization of internet technology, (II) the democratization of information, and (III) the democratization of social capital. Figure 1 visualizes these findings.

Insert Figure 1 somewhere here

It also shows that on the most basic level the phenomenon consists of two different forms of democratization: democratization through technology and democratization of technology itself (Carroll and Hackett, 2006). The internet-based democratization of information and of social capital fall into the former category while the democratization of internet technology falls into the latter. Apart from presenting these key democratization developments, Figure 1 
shows the key developments' respective key facets or sub-themes, based on the findings of the integrative review. For example, social self-representation, social connectivity and social mobilization are the key facets of the internet-based democratization of social capital. The arrows in Figure 1 indicate the main influences between the two different forms of democratization that have been elicited from the literature. Despite the socio-technological conceptualization that societal and technological developments influence each other, the oneway arrows reflect the finding that the democratization of internet technology is a necessary enabler for the internet-based democratization of brand management but that its presence alone is not sufficient evidence for the occurrence of the phenomenon. Only the presence of either of the two other key developments or any of their key facets provides sufficient evidence for the occurrence of the internet-based democratization of brand management in a particular situation. All these key developments and findings are further explained and discussed one-by-one in the following sections.

\subsection{The Democratization of Internet Technology}

As previously described, in the pre-internet age, many stakeholders, particularly consumers, had very little power in their everyday dealings with organizations (Berthon and Hulbert, 2003; Pitt et al., 2002; Rezabakhsh et al., 2006). However, with the advent of new technologies the power imbalance between organizations and their stakeholders has in many cases shifted considerably. The internet, in particular, has been a huge contributory factor to this shift - along with internet usage-related technologies such as more affordable PCs, easyto-use software, digital TV, still and video cameras, broadband and mobile telecommunications (Argenti, 2006; Brown, 2009; Pires et al., 2006). For example, in the

pre-internet age generally only commercial organizations had the technological and financial means to produce and broadcast audio-visual material such as video clips, whereas today 
most people in the industrialized world have access to the necessary equipment listed above. Therefore, based on the conceptualization of democratization as a process of transition from a less to a more democratic form of power sharing, the developments that led to the widespread availability of hardware and software for internet access and the infrastructure for internet connectivity, can - at least on a technological level - be interpreted as a democratization process (Figure 1).

Nonetheless, an important emerging theme in the literature is that democratization describes a process in which inequalities of power are reduced but by no means eliminated. Therefore, in many instances a technology-based social divide can still be observed. And this applies not only to less developed regions and continents but also to leading countries in the industrialized world. For example, in European countries like Sweden or the UK there is, at least to a certain extent, evidence of a digital divide and therefore social exclusion (Ferlander and Timms, 2007). Although more and more users are technically enabled to access the internet and other communication infrastructures they might not necessarily have the right digital media literacy skills required to engage with the new possibilities of the internet democratization (Cammaerts, 2008; Livingstone, 2008). Knowing how to use the available software and hardware resources might be equally - if not even more - important than just the technical access to it.

The democratization of access to internet technology is an essential enabler for the internet-based democratization of brand management (Figure 1). But its presence alone is not sufficient as an indicator of the occurrence of the socio-technological phenomenon under investigation. Only when people possess the necessary skills to use the available technology, can it be applied to increase a brand stakeholder's power. 


\subsection{The Internet-based Democratization of Information}

From a perspective of user empowerment, access to the internet presents digitally literate consumers and other stakeholders of organizations with new opportunities: (i) to overcome information asymmetries that characterize traditional markets (Christodoulides, 2009; Pitt et al., 2002; Rezabakhsh et al., 2006; Weber, 2007), (ii) to take on a more active role in creating information about organizations and their brands (Anderson, 2006; Gillin, 2007; Li and Bernoff, 2008; Rezabakhsh et al., 2006), and (iii) to disseminate this information to a wide audience with much greater ease (ibid). Information-related abilities have therefore been identified as one of the key forms of occurrence of the internet-based democratization of brand management (Figure 1).

\subsubsection{The Internet-based Democratization of Information Access}

The internet has empowered consumers and other stakeholders by giving them unparalleled access to a massive body of information, for example information about products, organizations, markets and entire industries (Harrison et al., 2006; Rezabakhsh et al., 2006; Smith and Zook, 2011). Furthermore, the internet offers an unprecedented mix of immediacy, searchability and interactivity compared with other information sources, such as traditional advertising (Harrison et al., 2006; Li and Bernoff, 2008). The majority of the information available on the internet itself, for example via search engines such as Google, is virtually free of charge to any user, making the search costs considerably lower when compared with many previously existing databases and archives (Keen, 2007; Verona and Prandelli, 2002).

The available information on the internet might represent an insurmountable information overload for some users, while for others it can minimize relative market power between organizations and consumers or other stakeholders when it comes to information asymmetry. The locus of power is not necessarily completely shifting but inequalities appear to be 
decreased through means such as search engines or price comparison websites. Nonetheless, similar to the technical literacy skills issue mentioned above, some authors point out that where and how to find the right information on the internet can equally be a struggle for users without the right internet literacy skills (e.g. Brants and Frissen, 2003).

When it comes to the brand meaning co-creation process, internet literate users are able to enrich their own experience of a brand through accessing previously unavailable brand manifestations via the internet, for example through searching for information about a brand from a distant geographical area. This access to additional brand manifestations can be interpreted as one form of occurrence of the internet-based democratization of brand management phenomenon since it can have a positive impact on, for instance, a consumer's legitimate power in relation to a particular organization (Figure 1).

In contrast to these user-initiated activities on the internet, which most organizations hardly have an influence on, many companies use the concept of providing access to information online to their advantage, in terms of brand manifestation management, through their own organization-initiated activities. A case in point is a company offering customers access to additional information about the latest products on its website. The advantage here is that the organization can, of course, control the content of the information provided, in contrast to, for example, an independently-run product review website. If a company owns an internet property, for instance an online community website, it might also be able to allow only selected users to access it and the information it provides. One example of this practice would be a customer relationship management activity where the organizing firm invites only certain users or customers to take part with exclusive access to content which can potentially strengthen the invited customers' loyalty (Bhalla, 2011).

It can be concluded that there are certain limitations to the internet-based democratization of information access that need to be taken into account. Nonetheless, in any case, the 
democratization of information access is just one of various information-related empowerment processes. On another level, internet literate users are able to enrich their brand experience by not only accessing additional information on the web but also actively participating in the creation of information about brands on the internet.

\subsubsection{The Internet-based Democratization of Information Creation}

A belief in the freedom of information was a strong motivating factor in the development of the internet from the outset (Berners-Lee and Fischetti, 2000; Hemetsberger, 2006a). However, generating content on the web was, for the overwhelming majority of users, too much of a challenge due to their lack of technical skills. As Smith (2008, p. 19) points out, "For the first 15 years of the internet's existence, creating content ... [was] the preserve of geeks who knew code or could navigate unprepossessing bulletin boards. Today, anyone can do it". Brand manifestations that may nowadays be created on the web, without needing to know software code, can range from simply posting a comment on somebody else's blog to creating your own blog or microblog with brand-related comments; from writing an online review about a product to producing and uploading a spoof ad for this brand on YouTube; from creating a profile on a social networking site for a brand to creating an entry on Wikipedia about the particular product, service or organization. The ability to create such brand manifestations can increase, for instance, the reward or coercive power of an organization's brand stakeholders. As stated earlier, people are no longer necessarily just passive recipients or targets of an organization's marketing and communications activities, but can potentially, more than ever before, become active producers and publishers or broadcasters in their brand meaning co-creation relationships with organizations (Argenti, 2006; Gregory, 2007; McConnell and Huba, 2007). The internet-based democratization of 
information creation can therefore be construed as another form of occurrence of the internetbased democratization of brand management phenomenon (Figure 1).

The main exception to these user-initiated information creation activities is organizationinitiated ones. When a company runs, for example, a creative competition for its customers on the internet, it potentially has a certain level of control over what is produced and published online (e.g. through moderation or selection processes; see Arnhold, 2010). The literature provides evidence that some organizations are even able to exploit content generated by - at first sight - empowered and independent internet users for their own commercial purposes (e.g. Cova and Dalli, 2009). Examples of these kinds of beneficiaries are commercial UGC platforms, such as the social networking site Facebook, or blog hosting sites such as blogger.com (Cammaerts, 2008; Coté and Pybus, 2007). In this context it is questionable to what extent the contributors to these commercially-run UGC platforms can be seen as genuinely independent and free of commercial dependencies. Internet users who generate content on these commercial websites, i.e. sites that earn money through placing advertising or sponsorship around UGC, are to a certain extent exploited by these organizations. The rationale for this conclusion is that these organizations do not have to create the content for their advertising platforms themselves and can thus minimize their own labor costs (Cova and Dalli, 2009; Dumenco, 2010; Kim and Hamilton, 2006; Zwick et al., 2008).

This example of hypercapitalism (Graham, 2000) illustrates that while most organizations are increasingly losing power and control through the emergence of user-generated content on the internet, some corporations are able to gain power, and benefit tremendously from internet-based information creation. This situation also applies to the next key facet of the internet-based democratization of information phenomenon, which is focused on the dissemination of information on the internet. 


\subsubsection{The Internet-based Democratization of Information Dissemination}

Organizations have never been fully in control of the information that is communicated about them and their products in the public domain due to the activity of stakeholders such as the media and competitors (Fombrun and Rindova, 2000; Grigoryants and Schnetzer, 2008; Roehm and Tybout, 2006). Also, individual stakeholders, such as consumers, have always been able to share opinions on a product or organization through word-of-mouth, for example, by talking to family, friends and colleagues. However, when it comes to the dissemination of information to an audience wider than that, the opportunities in the preinternet age were limited. In contrast to that, nowadays virtually anyone with adequate digital literacy skills and access to the internet can use it as a personal communication and publishing or broadcasting platform to reach an audience far beyond family, friends and colleagues. The ability to disseminate brand manifestations via the internet increases, for instance, the reward power of an organization's brand stakeholders and therefore leads to a more democratic form of power sharing between this organization and its internet literate brand stakeholders. It can therefore be concluded that the internet-based democratization of information dissemination represents yet another form of occurrence of the internet-based democratization of brand management phenomenon (Figure 1).

A critical issue in this context is the crisis of credibility on the internet. Due, for instance, to a lack of control and accountability on the web, in many cases anybody can become a selfproclaimed expert and influence those who are not able to distinguish between quality and nonsense (Constantinides and Fountain, 2008; Keen, 2007). This democratization of expertise can lead to error and opportunism (Guernsey, 2000). Wikipedia can be used as an example where people have contributed material that is incorrect, biased and potentially defamatory, for instance, in the case of politicians such as George W. Bush (The Economist, 2006). In 
terms of doubts about the credibility of internet content, the literature provides evidence that all kinds of content can be faked on the internet (e.g. Cammaerts, 2008; Deuze, 2008). Lim (2009) and Rezabakhsh et al. (2006) also point out that search engine results can be manipulated through various search engine marketing methods.

Despite these limitations, the findings of the literature review indicate that each of the three facets of the democratization of information phenomenon provides opportunities for an organization's internet literate brand stakeholders to access and/or create brand manifestations to increase their reward, coercive, expert and/or legitimate power. Each of those three empowerment processes represents - enabled by the democratization of internet technology - a potential form of occurrence of the internet-based democratization of brand management phenomenon (Figure 1).

However, this conclusion is not unanimous but contested by some critics. Boyd (in Johnson, 2009), for instance, questions the internet-based democratization of information even if users are provided with the necessary internet literacy skills, since for her the whole game has changed:

"we've made [content] creation and distribution more available to anyone, but at the same time we've made those things irrelevant. Now the commodity isn't distribution, it's attention - and guess what? Who gets attention is still sitting on a power law curve ... we're not actually democratising the whole system we're just shifting the way in which we discriminate".

This critique ties in with Locker's notion that an internet-based technology such as Twitter is "good for democracy, but it's not democratic" (in Henley, 2009). In the context of blogs, for instance, Cammaerts (2008) suggests that elites in society (e.g. well-known actors, politicians, or business leaders) generally have it easier when disseminating their ideas because, just by being elites, their blogs automatically get more attention than those of ordinary bloggers. It is therefore important to keep in mind that democratization does not mean democracy in terms of equal distribution of power - or attention. Social divides might 
thus still be observed in many cases despite an overall transition from a less to a more democratic form of power sharing when it comes to access, creation and dissemination of information on the internet.

Overall, however, examining the evolution of the internet from the previously discussed holistic, socio-technological perspective (Fuchs, 2005), it appears to be important to recognize that it has not only been a technology- and information-driven but also particularly a socially-driven phenomenon. People have been adopting and using the internet as part of their social lives (Anderson, 2007) and many of these internet technologies "rely for their power on social interactions" (Kelly, 2009, p. 122). This part of the internet-based democratization phenomenon will be further explored next.

\subsection{The Internet-based Democratization of Social Capital}

Although the internet was initially seen mainly as an information access and publishing mechanism, some involved in its technical development from an early stage state that the internet was also always social (e.g. Berners-Lee and Fischetti, 2000). For example, the first online newsgroups and discussion forums were started by developers and programmers right from the very beginning of the World Wide Web evolution (ibid). Even before that, in the 1980s, virtual communities, such as The WELL, were created as electronic dial-up bulletin board systems (Rheingold, 1991; Turner, 2005). Nonetheless, on the scale of a global mass phenomenon, the internet as a socially-oriented platform began to emerge in the late 1990s with applications such as Classmates.com, Sixdegrees.com and FriendsReunited.co.uk (Boyd and Ellison, 2008; Donath and Boyd, 2004; Jeffrey et al., 2009). Since then, particularly over the last few years, the social side of the internet has become very prominent due to the rise of further so-called social internet (e.g. Boyd and Ellison, 2008), social web (e.g. Brown, 2009), social media (e.g. Safko and Brake, 2009), social software (e.g. Tepper, 2003), social 
computing (e.g. Parameswaran and Whinston, 2007) or Web 2.0 (e.g. O'Reilly, 2005) applications such as Facebook, Twitter, YouTube and Flickr, to name but a few. From this socially-oriented perspective, the internet provides new opportunities for technically literate consumers and other stakeholders of organizations

(i) to represent and express themselves as individuals or groups of stakeholders in front of an organization and other audiences in a diverse number of ways. For instance, through the creation of their own websites, blogs, microblogs, discussion forums or profiles on social networking sites (Cova and Pace, 2006; Hemetsberger, 2005; Kozinets, 2001; Proctor and Kitchen, 2002; Schau and Gilly, 2003; Simmons, 2008; Webb and Burgoyne, 2009),

(ii) to connect with others beyond their geographical proximity. For example, to form a worldwide brand or anti-brand community (Cova and Pace, 2006; Hollenbeck and Zinkhan, 2006 and 2010; Kucuk, 2008; Muñiz and O’Guinn, 2001), and

(iii) to interact with or mobilize others. For example, to jointly develop new products online (Füller et al., 2007; Hemetsberger, 2005 and 2006b; Kozinets et al., 2008; Palmer and Koenig-Lewis, 2009; Piller et al., 2005).

In these examples, internet users may benefit not only from the actual information or knowledge that is exchanged or created in the process, but particularly from social, communal and relationship-oriented aspects such as sharing, collaborating and bonding with others (Belk, 2010). In this context, even individual stakeholders, such as consumers, are enabled to make themselves heard through the internet to an unprecedented extent not only as individuals or groups that create and disseminate information but also as individual or social entities who actively want to express themselves to and connect and interact with others. It may thus be concluded that digitally literate consumers and other stakeholders are not only 
more empowered on a technological or information-related basis through the new opportunities that the internet offers but also on a social level - at least potentially - in their dealings with organizations. Consequently, as indicated in Figure 1, it may thus be inferred that the democratization of internet technology has not only enabled a democratization of information but also a democratization of social capital.

Based on a review of the social capital literature, the term has initially been defined here as a beneficial social asset - to individuals and/or groups - that comprises (i) social connections and (ii) the resources that may be mobilized through these connections (Bourdieu, 1986; Burt, 1992; Coleman, 1988 and 1990; Nahapiet and Goshal, 1998). Apart from these two main forms of social capital, additionally social self-representation is introduced as a third form, specifically for the present internet-related context. Social capital in the form of social self-representation opportunities is seen as relevant in the present online context since it can be interpreted as a prerequisite for the other two forms. The various opportunities for expressing yourself to the world via the internet (see Figure 2, point 1) may have a considerable impact on the development of a person's or group's online relationships and networks (point 2) and subsequently the resources that might be accessed through these connections (point 3).

Insert Figure 2 somewhere here

\subsubsection{The Internet-based Democratization of Social Self-representation}

In the literature about postmodern consumption it has been postulated that many people are seeking both individualistic as well as communal experiences in life (Belk, 2010; Firat and Venkatesh, 1995; Simmons, 2008). The internet appears to be able to provide both these kinds of experiences to its users. It can function as "virtual glue" (Simmons, 2008, p. 305) 
that people can use to bond together in an increasingly fragmented world. It can, at the same time, also be approached as a platform for individualistic experiences rather than any bonding benefits (Parameswaran and Whinston, 2007). When it comes to communal experiences, postmodern consumers show new forms of sociality based not only upon direct face-to-face or synchronous internet-mediated interaction with others, but also through a more indirect form of an internet-based self-exhibition in front of others (Cova and Pace, 2006; Dholakia et al., 2004; Hemetsberger, 2005; Litvin et al., 2008; Simmons, 2008). Blogs, for instance, can not only be interpreted as a means of internet-mediated dissemination of knowledge, but also as a platform for social self-representation. In this sense, the internet may represent "the ultimate democratization of self-expression" (Watson, 2009). Microblogs, such as Twitter, have become particularly prominent in this respect. Another case is virtual worlds (e.g. Second Life), in which users can create their own profile and avatar totally from scratch and therefore a completely new me (Krishnamurthy and Dou, 2008).

In the specific democratization context, it has to be taken into account that new internetbased self-representation opportunities have also led to new possibilities for an organization's brand stakeholders to create brand manifestations. These manifestations may contribute to the creation of brand meanings of, for example, a corporate brand that potentially stand in sharp symbolic contrast to the brand meaning that the corporation itself intends to convey through its own corporate brand meaning co-creation activities (see e.g. Thompson et al., 2006, and their concept of the Doppelgänger brand image). A case in point is a group of Virgin Atlantic flight attendants who criticized the airline and its passengers on the social networking site Facebook (Conway, 2008). The Facebook site provided the flight attendants with a new platform to create a brand manifestation by expressing themselves and their opinions about the airline and its passengers. This previously unavailable platform of internet-based social self-representation can be interpreted as a means that has increased their ability to use 
coercive power towards their employer. The internet-based democratization of selfrepresentation can in this context therefore be construed as yet another form of occurrence of the internet-based democratization of brand management phenomenon (Figure 1).

However, there is also another angle that needs to be taken into account in the present context. For example, when institutions actively try to manipulate or fake user selfrepresentations on the internet. One early case in point was Reckitt Benckiser with their cleaning product brand Cillit Bang and their PR agency Cohn \& Wolfe who set up not only a fake blog but also a fake blogger named Barry Scott who left marketing messages in blogs and posts on other websites (Coates, 2005; Johnson, 2005; Palmer and Koenig-Lewis, 2009).

\subsubsection{The Internet-based Democratization of Social Connectivity}

Although the internet has been linked with decreases as well as increases in traditional social capital (e.g. Ellison et al., 2007, Valenzuela et al., 2008; Wellman et al., 2001; Williams, 2006), in terms of social connectivity, a strong rationale has emerged in the literature showing that the internet is in principle able to broaden users' opportunities to build and maintain networks with others (e.g. Donath and Boyd, 2004). This rationale is often based on a concept developed originally by Granovetter (1973) who differentiates between weak ties and strong ties. Based on his concept, the internet may not necessarily offer users per se the opportunity to increase the number of strong ties (i.e. emotionally close, long-term relationships), but it may well allow a person to increase the weak ties (i.e. emotionally distant, casual relationships). For example, social networking sites or blogs are particularly suited to maintaining weak ties easily (e.g. Donath and Boyd, 2004; Ferlander and Timms, 2007; Valenzuela et al., 2008). From this weak ties perspective, the internet appears to provide at least bridging social capital, which means it allows individuals or groups to make connections with other individuals or groups, potentially from completely different 
backgrounds or geographical areas (Putnam, 2000). These kinds of social connections might, for most members of a particular network, only have the characteristics of tentative relationships but what they might lack in depth they can make up in breadth (Williams, 2006).

Looking at the power imbalance between organizations and their brand stakeholders from a perspective of weak ties and bridging social capital, the internet allows consumers and other stakeholders, potentially, to connect more easily with people who have a specific joint interest, purpose or background (Preece, 2000). This may be considered as beneficial for internet users in terms of their stakeholder power, for instance, when it comes to seeking advice from existing or former customers of an organization, for example, in the context of specific banking services (Berger and Messerschmidt, 2009). Connecting with others allows an organization's brand stakeholders, in such a context, to decrease the organization's expert power. Thus, the internet-based democratization of social connectivity can be confirmed as a form of occurrence of the internet-based democratization of brand management phenomenon (Figure 1).

In the pre-internet age, it was mainly organizations that had the resources to connect with thousands of people worldwide via, for example, advertising, PR or direct marketing activities. Nowadays, virtually any internet literate user can potentially connect with a large number of other users. This weak ties-based democratization of social connectivity can potentially cause a considerable erosion of control over brand meaning co-creation processes for organizations. However, these points about weak tie relationships only encapsulate one side of the discussion in the social capital literature. Apart from bridging social capital, which is mainly linked to weak tie relationships and a primary focus on connectivity, there is another form of social capital called bonding social capital, which is mainly linked to the mobilization of resources through strong tie relationships (Putnam, 2000). 


\subsubsection{The Internet-based Democratization of Social Mobilization}

The internet provides its users with bridging social capital by enabling them to create and maintain weak tie relationships. A drawback of this internet-based bridging social capital is that these kinds of social connections and networks are usually considered as rather superficial and casual. They are considered unlikely to provide members of a network with valuable social resources such as strong emotional or substantive support when needed (Donath and Boyd, 2004; Valenzuela et al., 2008; Williams, 2006). Bonding social capital, in contrast to bridging social capital, occurs when individuals or groups provide close emotional or substantive support for one another (Putnam, 2000).

Some literature provides evidence that the internet is also able to generate bonding social capital for at least some of its users (e.g. Ferlander and Timms, 2007). In this context, the concept of social mobilization becomes relevant (e.g. Hara and Estrada, 2005). While social connectivity is mainly about access to other individuals and groups, social mobilization is about the resources that then may be available to a member of a network through its other members. The extent of these resources, which can be mobilized through a network, depends on the intensity, trust and reciprocity of the relationships within the network (Granovetter, 1973). This suggests that while bridging social capital depends more on the breadth and quantity of relationships, bonding social capital depends primarily on the depth and quality.

Although it might at first glance seem unlikely that internet users bond with friends of friends or even strangers on the internet on a similarly intense and reciprocal level as they might with close family or friends it should not be underestimated that individuals or groups of joint specific interest, purpose or background may provide each other with a substantial amount of emotional, informational, financial and/or human (e.g. working hours) resources that would usually only be expected in a strong tie relationship. 
An example of internet-based social mobilization, where individuals and groups have benefited from substantial reciprocal services in terms of dedicated time and labor or human resources (i.e. voluntary and therefore unpaid working hours), is Lugnet.com, the international LEGO users group network of so-called AFOLs, adult fans of LEGO. This global online community of LEGO enthusiasts is user-driven, created by fans for fans. Here, on different forums, hundreds of LEGO enthusiasts can actively discuss all kinds of topics related to LEGO products in great length and depth over weeks, months and even years. They can share their ideas as well as their passion for the products and brand. They showcase their own LEGO creations or co-develop and co-design complex new LEGO worlds based on virtual or real LEGO bricks constructions. Lugnet.com enables its users not only to mobilize other enthusiasts to co-create new LEGO-related brand manifestations but also to provide access for others to these manifestations on a broader scale. The internet enables individuals and groups in this context to mobilize others which can increase, for example, their legitimate power towards the LEGO organization (see also Hatch and Schultz, 2010). Based on this example the internet-based democratization of social mobilization can thus be identified as another form of occurrence of the internet-based democratization of brand management phenomenon (Figure 1).

The findings of the literature review indicate overall, in terms of (i) social selfrepresentation, (ii) social connectivity, and (iii) social mobilization, that each of these three facets of the democratization of social capital phenomenon provides opportunities for an organization's internet literate brand stakeholders to access and/or create brand manifestations to increase their reward, coercive, expert and/or legitimate power. Based on the evidence and examples presented within this review, it can therefore be inferred that the democratization of social capital, in conjunction with the democratization of internet 
technology, should be considered as being another essential part of the multi-layered nature of the internet-based democratization of brand management (see Figure 1).

\section{Conclusions}

The aim of this paper was to develop a deeper understanding of the multi-layered nature of the internet-based democratization of brand management as a holistic, socio-technological phenomenon. The insights gained from the integrated review have clarified the phenomenon's basic structure on three different levels. Firstly, on the most basic level, the literature review shows that the explored phenomenon consists principally of two different kinds of democratization: democratization of technology and democratization through technology. On a second level, the study reveals that the democratization of internet technology has led to two different kinds of democratization through technology: a democratization of information and a democratization of social capital. On a third level, the review provides evidence that each of these democratization developments consists of various internet-based democratization facets. Of particular relevance appear to be the six facets which can be associated with the democratization of information or the democratization of social capital. Each of these six internet-based facets enables a more democratic form of power sharing between an organization and its digitally literate brand stakeholders in the context of the creation of brand manifestations and/or the access provision to them, compared to previous circumstances.

Based on a balanced, stakeholder-integrating and brand manifestation-oriented conceptualization of brand management, these findings have considerable managerial consequences. Most notably, brand management has been democratized through the internet as a radical change agent. The power within brand meaning co-creation relationships between organizations on the one hand and their internet-empowered stakeholders on the other, has in 
many cases increasingly shifted towards the organizations' brand stakeholders. This is due to an unprecedented shift of resource availability on the internet regarding the creation of and access provision to brand manifestations. Internet-based brand meaning co-creation activities can now be stakeholder-initiated as well as organization-initiated at any stage of the process. Empowered by the internet, technically literate brand stakeholders of an organization have more than ever before - a choice of moving between different levels of activity and involvement regarding brand meaning co-creation. They can (1) in the traditional, rather passive sense, co-create meaning out of the brand manifestations which they experience that are provided to them by the brand's focal organization and/or other stakeholders; (2) become more active through co-creating not only brand meaning but also brand manifestations in collaboration with the brand's focal organization and/or other brand stakeholders; or (3) create brand manifestations on a previously unparalleled magnitude by themselves outside the control of anybody else, including the brand's focal organization. Looking at the wider implications for the brand management discipline, these findings correspond with an emerging call in recent literature (e.g. Fischer and Smith, 2011) for the development of a new brand management paradigm. Our research substantiates the notion that this new approach needs to integrate not only organization-initiated but also stakeholder-initiated brand management activities.

In terms of future research directions, the in-depth exploration of power structures within open source communities, such as the Linux operating system project (Hemetsberger, 2006a and 2006b; Kozinets et al., 2008; O’Reilly, 2005; Pitt et al., 2006), appears to have great potential. The difference between Linux and other examples discussed in this paper is that from a democratization perspective we move into the territory of so-called open source brands (Pitt et al., 2006) or community brands (Füller et al., 2008) where power and control over core brand manifestations, such as the development of new products, is radically more 
decentralized and heterarchical compared to conventional product or corporate brands (Pitt et al., 2006; Schroll et al., 2011). We expect this area of research to provide valuable insights into the development of a new brand management paradigm that will be applicable not only to open source and community brands but also conventional product and corporate ones.

In terms of the limitations of our research, it needs to be acknowledged that the priority has been to clarify the multi-layered nature of the internet-based democratization of brand management as a holistic, socio-technological phenomenon. We subsequently suggest that it is useful to consider the basic structure of this phenomenon in terms of the three key developments and their respective key facets as presented in this paper (Figure 1). Nonetheless, although we have separated these key developments and facets analytically, and although we have portrayed various influences of key developments as unilateral in the idealtypical conceptualization of this complex topic, we recognize that many aspects of this phenomenon are in fact interrelated and multilateral.

Despite the limitations, overall the paper provides some direction for future research through its contribution towards the clarification of the multi-layered nature of the internetbased democratization of brand management phenomenon. Moving forward towards the development of a new, more balanced and stakeholder-integrating paradigm appears to be essential, since the lack of an adequate framework has implications not only for brand management but marketing as a whole. 
Figure 1: The three socio-technological key developments of the internet-based democratization of brand management

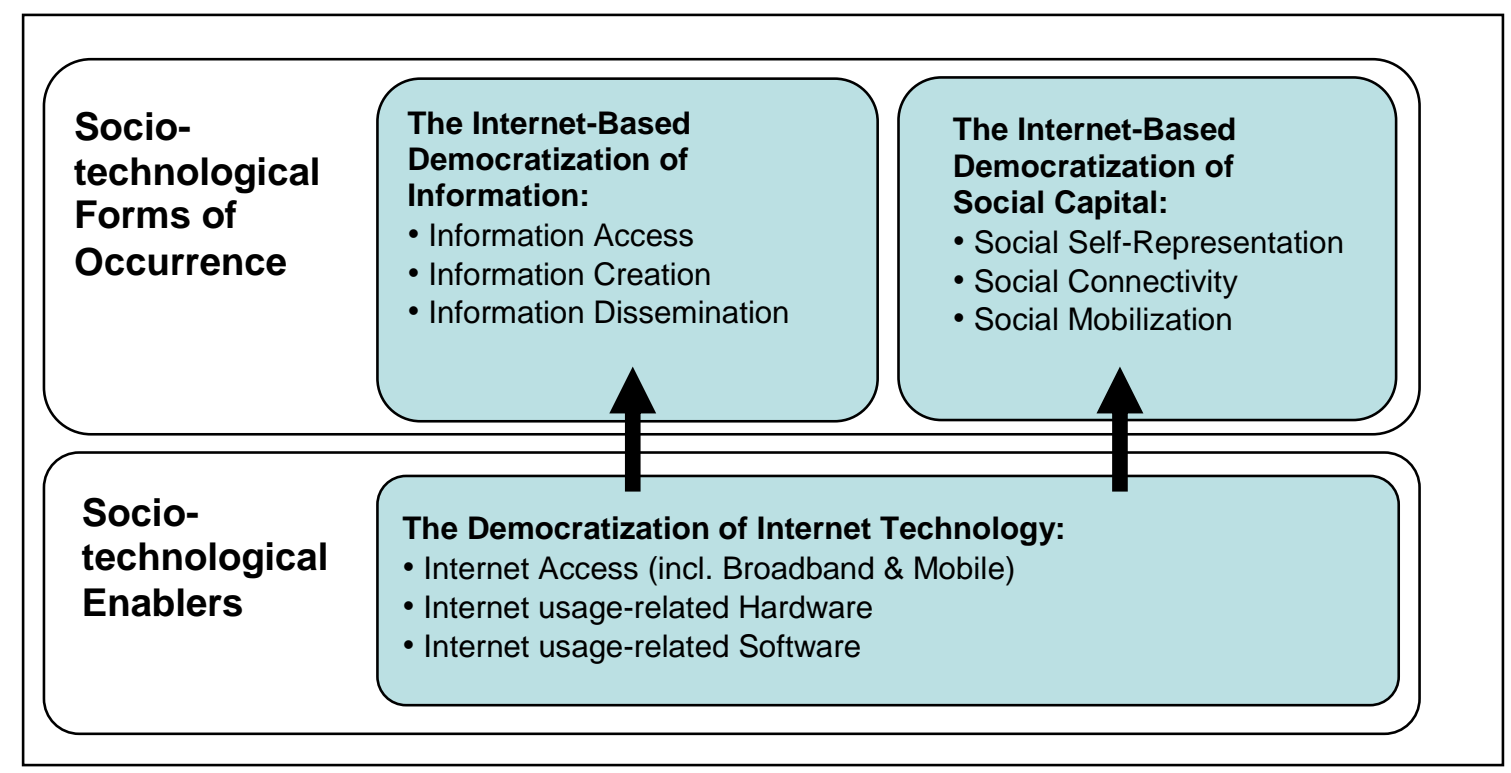

\section{Figure 2: Key forms of internet-based social capital}

1. An Individual's or Group's Internet-Based Self-Representation Opportunities:

- Own websites, blogs, discussion forums, profiles on social networking sites, etc.

- Contributions to other individuals', groups' or organizations' websites, blogs, discussion forums, social networking profiles, etc.

- Further user-generated content (UGC), for example, videos on YouTube or photographs on Flickr

- Emails, instant messaging, chat rooms, etc.

2. An Individual's or Group's Internet-Based Connections with:

- Other individuals

- Other groups

- Other organizations

3. The Potential and Actual Resources that an Individual or Group Are Able to Mobilize Through Their Internet-Based Connections:

- Financial resources

- Emotional resources

- Labor resources

- Informational resources, etc. 


\section{References}

Allen C, Fournier S, Miller F. Brands and their meaning makers. In: Haugtvedt C, Herr P, Kardes F, editors. Handbook of Consumer Psychology. Mahwah, NJ: Lawrence Erlbaum Associates; 2008. p. 781-822.

Anderson C. The long tail. London, UK: Random House; 2006.

Anderson P. What is web 2.0? Ideas, technologies and implications for education. JISC Technology and Standards Watch Report. 2007, February. http://www.jisc.ac.uk/media/documents/techwatch/tsw0701b.pdf [14 August 2009].

Antorini YM, Schultz M. Principles for the Second Wave of Corporate Branding. In: Schultz M, Antorini YM, Csaba FF, editors. Corporate Branding. Copenhagen, Denmark, Copenhagen Business School Press, 2005. pp. 219-232.

Argenti PA. How technology has influenced the field of corporate communication. Journal of Business and Technical Communication 2006; 20 (3): 457-370.

Arnhold U. User Generated Branding: An Exploration of a New Field of Study Focusing on the Effectiveness of Participatory Communication Programmes. Wiesbaden, Germany: Gabler; 2010.

Belk R. Sharing. Journal of Consumer Research 2010; 36 (5): 715-34.

Berger SC, Messerschmidt CM. Babbling before banking? Online communities and pre-purchase information seeking. International Journal of Bank Marketing 2009; 26 (6): 446-466.

Berners-Lee T, Fischetti M. Weaving the web: the past, present and future of the world wide web by its inventor. London, UK: Texere; 2000.

Berners-Lee T, Hall W, Hendler JA, O’Hara K, Shadbolt N, Weitzner DJ. A Framework for Web Science. Foundations and Trends in Web Science 2006; 1 (1): 1-130.

Berthon P, Holbrook MB, Hulbert JM, Pitt L. (2007): Viewing Brands in Multiple Dimensions. MIT Sloan Management Review, 2007; 48 (2): 37-45. 
Berthon P, Hulbert JM. Marketing in metamorphosis: breaking boundaries. Business Horizons 2003; 46 (3): 31-40.

Berthon P, Pitt LF, Campbell C. Does brand meaning exist in similarity or singularity? Journal of Business Research 2009; 62 (3): 356-361.

Berthon P, Pitt LF, Chakrabarti R, Berthon J-P, Simon M. Brand Worlds. From Articulation to Integration. Journal of Advertising Research 2011; 51 (March Supplement): 182-188.

Bhalla G. Collaboration and Co-creation: New Platforms for Marketing and Innovation. New York, NY: Springer; 2011.

Bourdieu P. The forms of capital. In: Richardson JG, editor. Handbook for Theory and Research for the Sociology of Education. New York, NY: Greenwood; 1986. p. 241-258.

Box JMF. The Power of Consumer Organisations. European Journal of Marketing 1982, 16 (6): 319.

Boyd DM, Ellison NB. Social network sites: definition, history, and scholarship. Journal of Computer-Mediated Communication 2008; 13: 210-230.

Brants K, Frissen V. Inclusion and exclusion in the Information Society. Final Deliverable, The European Media and Technology In Everyday Life Network, 2000-2003; 2003. http://www.lse.ac.uk/collections/EMTEL/reports/brants_2003_emtel.pdf [10 January 2010].

Brown R. Public relations and the social web. How to use social media and web 2.0 in communications. London, UK: Kogan Page; 2009.

Brown S, Kozinets RV, Sherry JF Jr. Teaching Old Brands New Tricks: Retro Branding and the Revival of Brand Meaning. Journal of Marketing 2003; 67 (3): 19-33.

Burmann C. A Call for 'User-Generated Branding'. Journal of Brand Management 2010, 18 (1): $1-4$.

Burmann C, Arnhold U. User generated branding. Münster, Germany: LIT; 2008. 
Burt R. Structural holes: the social structure of competition. Cambridge, MA: Harvard University Press; 1992.

Cammaerts B. Critiques on the participatory potentials of web 2.0. Communication, Culture \& Critique 2008; 1 (4): 358-377.

Carroll WK, Hackett RA. Democratic media activism through the lens of social movement theory. Media, Culture \& Society 2006; 28 (1): 83-104.

Christodoulides G. Breaking free from the industrial age paradigm of branding. Journal of Brand Management 2008; 15 (4): 291-293.

Christodoulides G. Branding in the post-internet era. Marketing Theory 2009; 9 (1): 141-144.

Coates T. On Cillit Bang and a new low for marketers. 2005.

http://www.plasticbag.org/archives/2005/09/on_cillit_bang_and_a_new_low_for_marketers/ [16 January 2010]

Coleman JS. Social capital in the creation of human capital. American Journal of Sociology 1988: 94 (supplement): s95-s120.

Coleman JS. Foundations of social theory. Cambridge, MA: Belknap Press of Harvard University Press; 1990.

Constantinides E, Fountain SJ. Web 2.0: Conceptual foundations and marketing issues. Journal of Direct, Data and Digital Marketing Practice 2008; 9 (3): 231-244.

Conway L. Virgin Atlantic sacks 13 staff for calling its flyers 'chavs'. The Independent Online; 2008, November 1. http://www.independent.co.uk/news/uk/home-news/virgin-atlantic-sacks13-staff-for-calling-its-flyers-chavs-982192.html [18 March 2010].

Coté M, Pybus J. Learning to Immaterial Labour 2.0: MySpace and Social Networks. Ephemera: Theory \& Politics in Organization 2007; 7 (1): 88-106.

Cova B, Dalli D. Working Consumers: The Next Step in Marketing Theory? Marketing Theory 2009; 9 (3): 315-339. 
Cova B, Pace S. Brand community of convenience products: new forms of customer empowerment - the case 'my Nutella The Community'. European Journal of Marketing 2006; 40 (9/10): 1087-1105.

Creswell JW. Qualitative Inquiry \& Research Design. Choosing Among Five Approaches. $2^{\text {nd }}$ ed., Thousand Oaks, CA: Sage; 2007.

de Chernatony L. From Brand Vision to Brand Evaluation. Oxford, UK: Butterworth-Heinemann; 2001.

Deuze M. Corporate appropriation of participatory culture. In: Carpentier N, Livingstone S, editors. Participation and media production: critical reflections on content creation. Newcastle upon Tyne, UK: Cambridge Scholars Publishers; 2008. p. 27-40.

Dholakia UM, Bagozzi RP, Klein Pearo L. A social influence model of consumer participation in network- and small-group-based virtual communities. International Journal of Research in Marketing 2004; 21: 241-263.

Dumenco S. Be Honest: What's Your Real Twitter and Facebook ROI? AdvertisingAge Online, 11th January 2010. http://adage.com/mediaworks/article?article_id=141381 [16 January 2010]

Donath J, Boyd D. Public displays of connection. BT Technology Journal 2004; 22 (4): 71-82.

(The) Economist. Open, but not as usual. 18th March 2006, p. 73-75. http://web.ebscohost.com/ehost/delivery?vid=8\&hid=113\&sid=bf6dbe98-ec39-4d9f-91ce62e9276b7267\%40sessionmgr113 [18 January 2010]

Ellison NB, Steinfield C, Lampe C. The benefits of Facebook "Friends": social capital and college students' use of online social network sites. Journal of Computer-Mediated Communication 2007; 12 (4): article 1. http://jcmc.indiana.edu/vol12/issue4/ellison.html [10 November 2009]. 
Esmann Andersen S, Nielsen AE. The City at Stake: 'Stakeholder Mapping' the City. Culture Unbound: Journal of Current Cultural Research 2009; 1: 305-329.

Ferlander S, Timms D. Social capital and community building through the internet: a Swedish case study in a disadvantaged suburban area. Sociological Research Online 2007; 12 (5). http://www.socresonline.org.uk/12/5/8.html [16 October 2009].

Firat AF, Venkatesh A. Liberatory postmodernism and the reenchantment of consumption. Journal of Consumer Research 1995; 22 (3): 239-267.

Fisher D, Smith S. Cocreation is chaotic: What it means for marketing when no one has control 2011; 11 (3): 325-350.

Fombrun CJ, Rindova VP. The road to transparency: reputation management at Royal Dutch/Shell. In: Schultz M, Hatch MJ, Holten Larsen M, editors. The Expressive Organization. Oxford, UK: Oxford University Press; 2000. p. 77-96.

Fournier S, Avery J. The uninvited brand. Business Horizons 2011; 54: 193-207.

French Jr JRP, Raven B. The bases of social power. In: Cartwright D, editor. Studies in social power. Ann Arbor, MI: University of Michigan, Institute for Social Research; 1959. p. 150167.

Fuchs C. The internet as a self-organizing socio-technological system. Cybernetics \& Human Knowing 2005; 12 (3): 57-81.

Füller J, Jawecki G, Mühlbacher H. Innovation creation by online basketball communities. Journal of Business Research 2007; 60: 60-71.

Füller J, Luedicke MK, and Jawecki G. How Brands Enchant: Insights From Observing Community-Driven Brand Creation. Advances in Consumer Research 2008, Vol. 35, Memphis, TN: Association for Consumer Research.

Gillin P. The New Influencers. Sanger, CA: Quill Driver Books; 2007. 
Graham P. Hypercapitalism. A Political Economy of Informational Idealism. New Media \& Society 2000; 2 (2): 131-156.

Granovetter M. The strength of weak ties. American Journal of Sociology 1973; 78 (6): 13601380.

Gregory A. Involving stakeholders in developing corporate brands: the communication dimension. Journal of Marketing Management 2007; 23 (1/2): 59-73.

Grigoryants N, Schnetzer U. Innovative brand management in the 'web 2.0 age'. Research paper presented at The Thought Leaders International Conference on Brand Management. Birmingham, UK; 2008, 15-16 April.

Grugel J. Democratization. A critical introduction. Basingstoke, UK: Palgrave Macmillan; 2002. Guernsey L. Suddenly, Everybody's an Expert on Everything. New York Times, 3rd February 2000. http://www2.hawaii.edu/ lollis/psc330-NYT-Knowledge.doc [18 January 2010]

Gummesson E. Relationship marketing and a new economy: it's time for de-programming. Journal of Services Marketing 2002; 16 (7): 585-589.

Halford S, Pope C, Carr L. A Manifesto for Web Science. In: Proceedings of the WebSci10: Extending the Frontiers of Society On-Line, April 26-27th, 2010, Raleigh, NC: US. Handelman JM. Corporate identity and the societal constituent. Journal of the Academy of Marketing Science 2006; 34 (2): 107-114.

Hara N, Estrada Z. Analyzing the mobilization of grassroots activities via the internet: a case study. Journal of Information Science 2005; 31 (6): 503-514.

Harrison T, Waite K, Hunter GL. The internet, information and empowerment. European Journal of Marketing 2006; 40 (9/10): 972-993.

Hatch MJ, Schulz M. Toward a theory of brand co-creation with implications for brand governance. Journal of Brand Management 2010; 17 (8): 590-604. 
Heding T, Knudtzen CF, Bjerre M. Brand Management. Research, Theory and Practice. London, Routledge; 2009.

Hemetsberger A. Creative cyborgs: how consumers use the internet for self-realization. In: Menon G, Rao AR, editors. Advances in Consumer Research. Provo, UT: 2005; 32: 653-660.

Hemetsberger, A. Understanding consumers' collective action on the internet: a conceptualization and empirical investigation of the Free- and Open Source movement. Unpublished habilitation, research synopsis, University of Innsbruck School of Management, Department of Strategic Management, Marketing and Tourism; 2006a. http://www.hemetsberger.cc/publications/pdf/habilitation.pdf [17 August 2008].

Hemetsberger, A. When David becomes Goliath: ideological discourse in new online consumer movements. In: Pechmann C, Price L, editors. Advances in Consumer Research. Provo, UT: 2006b; 33: 494-500.

Henley J. The Power of Tweets. The Guardian, online, 31st October 2009. http://www.guardian.co.uk/theguardian/2009/oct/31/the-power-of-twitter [01 November 2009]

Hensel G. It's the others, stupid. An introduction to the new, social web. Presentation given at Fachhochschule Wiesbaden, Germany. November $4^{\text {th }} ; 2008$.

Hollenbeck CR, Zinkhan GM. Consumer activism on the internet: the role of anti-brand communities. In: Pechmann C, Price L, editors. Advances in Consumer Research. Provo, UT: 2006; 33: 479-485.

Hollenbeck CR, Zinkhan GM. Anti-Brand Communities, Negotiation of Brand Meaning, and the Learning Process: The Case of Wal-Mart. Consumption, Markets \& Culture 2010; 13 (3): $325-345$.

Jeffery S, Fenn C, Johnson B, Smith E, Coumbe J. A people's history of the internet: from Arpanet in 1969 to today. In: The Guardian, online; 2009, 23 October. 
http://www.guardian.co.uk/technology/interactive/2009/oct/23/internet-arpanet [25 October 2009]

Johnson B. Cleaner caught playing dirty on the net. The Guardian, online, 6th October 2005. http://www.guardian.co.uk/technology/2005/oct/06/newmedia.onlinesupplement [16 January 2010]

Johnson B. 'People looked at me like I was an alien'. Interview with Danah Boyd. The Guardian, online, 9th December 2009. http://www.guardian.co.uk/technology/2009/dec/09/interviewmicrosoft-researcher-danah-boyd [12 January 2010]

Keen A. The cult of the amateur. London, UK: Nicholas Breadley; 2007.

Kelly K. The new socialism. Wired; 2009, July. p. 120-125.

Kemming JD, Humborg C. Democracy and nation brand(ing): Friends or foes? Place Branding and Public Diplomacy 2010; 6 (3): 183-197

Kim E-G, Hamilton JW. Capitulation to capital? OhmyNews as alternative media. Media, Culture \& Society 2006; 28 (4): 541-560.

Kozinets RV. Utopian enterprise: articulating the meanings of Star Trek's culture of consumption. Journal of Consumer Research 2001; 28 (June): 67-88.

Kozinets RV, Hemetsberger A, Schau HJ. The wisdom of consumer crowds. Collective innovation in the age of networked marketing. Journal of Macromarketing 2008; 28 (4): 339354.

Kramer N. Foreword. In: Mooney K, Rollins N. The open brand. When push comes to pull in a web-made world. Berkeley, CA: AIGA New Riders; 2008, p. 6-7.

Krishnamurthy S, Dou W. Advertising with user-generated content: a framework and research agenda. Journal of Interactive Advertising 2008; 8 (2). http://www.jiad.org/article99 [07 November 2009] 
Kucuk SU. Negative double jeopardy: the role of anti-brand sites on the internet. Journal of Brand Management 2008; 15 (3): 209-222.

Li C, Bernoff J. Groundswell. Winning in a world transformed by social technologies. Boston, MA: Harvard Business Press; 2008.

Lim M. Postmodern paradigms and brand management in the 'search' economy. International Journal of Internet Marketing and Advertising 2009; 5 (1/2): 4-16.

Litvin SW, Goldsmith RE, Pan B. Electronic word-of-mouth in hospitality and tourism management. Tourism Management 2008; 29: 458-468.

Livingstone S. Engaging With Media - A Matter of Literacy? Communication, Culture \& Critique 2008; 1 (1): 51-62.

Louro MJ, Cunha PV. Brand Management Paradigms. Journal of Marketing Management 2001; $17(7 / 8): 849-875$.

McConnell B, Huba J. Citizen marketers. When people are the message. Chicago, IL: Kaplan; 2007.

McCracken G. Culture and Consumption II. Markets, meaning, and brand management. Bloomington, IN: Indiana University Press; 2005.

Merz M, He Y, Vargo SL. The evolving brand logic: a service-dominant logic perspective. Journal of the Academy of Marketing Science 2009; 37 (3): 328-344.

Mühlbacher H, Hemetsberger A. What the Heck is a Brand? An Attempt of Integration and its Consequences for Research and Management. Proceedings of the 7th International Congress of Marketing Trends, Venice 2008. http://www.escpeap.net/conferences/marketing/2008_cp/Materiali/Paper/Fr/Muhlbacher_Hemetsberger.pdf [08 August 2008] 
Mühlbacher H, Hemetsberger A, Thelen E, Vallaster C, Massimo R, Füller J, Pirker C, Schorn R, Kittinger C. Brands as Complex Social Phenomena. Proceedings of the Thought Leaders International Conference on Brand Management, Birmingham, UK; 2006.

Muñiz AM Jr, O’Guinn TC. Brand community. Journal of Consumer Research 2001; 27 (March): 412-432.

Nahapiet J, Ghoshal S. Social capital, intellectual capital, and the organizational advantage. Academy of Management Review 1998; 23 (2): 242-266.

Neisser D. The tidal wave of brand democratisation. Admap 2006; Issue 478 (December): 40-41. O’Guinn TC, Muñiz Jr AM. Towards a Sociological Model of Brands. In: Loken B, Ahluwalia R, Houston MJ, editors, Brands and Brand Management. Contemporary Research Perspectives. New York, NY: Routledge; 2010. p. 133-155.

O'Reilly T. What is web 2.0? Design patterns and business models for the next generation of software. 2005. http://www.oreillynet.com/pub/a/oreilly/tim/news/2005/09/30/what-is-web20.html [13 June 2008].

Palmer A, Koenig-Lewis N. An experiential, social network-based approach to direct marketing. Direct Marketing: An International Journal 2009; 3 (3): 162-176.

Parameswaran M, Whinston AB. Research issues in social computing. Journal of the Association for Information Systems 2007; 8 (6): 336-350.

Piller F, Schubert P, Koch M, Möslein K. Overcoming mass confusion: collaborative customer co-design in online communities. Journal of Computer-Mediated Communication 2005; 10 (4), article 8. http://jcmc.indiana.edu/vol10/issue4/piller.html [29 September 2009]

Pires GD, Stanton J, Rita P. The internet, consumer empowerment and marketing strategies. European Journal of Marketing 2006; 40 (9/10): 936-949.

Pitt LF, Berthon PR, Watson RT, Zinkhan GM. The internet and the birth of real consumer power. Business Horizons 2002; 45 (4): 7-14. 
Pitt LF, Watson RT, Berthon PR, Wynn D, Zinkhan GM. The penguin's window: corporate brands from an open-source perspective. Journal of the Academy of Marketing Science 2006; 34 (2): 115-127.

Plé L, Cáceres RC. Not always co-creation: introducing interactional co-destruction of value in service-dominant logic. Journal of Services Marketing 2010; 24 (6): 430-437.

Plunkett JW. Plunkett's Advertising \& Branding Industry Almanac 2011. Houston, TX: Plunkett Research; 2011.

Post JE, Preston LE, Sachs S. Redefining the corporation: Stakeholder management and organizational wealth. Stanford, CA: Stanford University Press; 2002.

Potter D, Goldblatt D, Kiloh M, Lewis P. Democratization. Cambridge, UK: Polity Press; 1997.

Prahalad CK, Ramaswamy V. Co-opting Customer Competence. Harvard Business Review 2000; 78 (January/February): 79-87.

Preece J. Online communities: designing usability and supporting sociability. New York, NY: John Wiley \& Sons; 2000.

Proctor T, Kitchen P. Communication in postmodern integrated marketing. Corporate Communications: An International Journal 2002; 7 (3): 144-154.

Putnam RD. Bowling alone: the collapse and revival of American community. New York, NY: Simon \& Schuster; 2000.

Quelch JA, Jocz KE. Greater good. How good marketing makes for better democracy. Boston, MA: Harvard Business Press; 2007.

Rezabakhsh B, Bornemann D, Hansen U, Schrader U. Consumer power: a comparison of the old economy and the internet economy. Journal of Consumer Policy 2006; 29: 3-36.

Rheingold H. Virtual reality. London, UK: Martin Secker \& Warburg; 1991.

Roehm ML, Tybout AM. When will a brand scandal spill over, and how should competitors respond? Journal of Marketing Research 2006; 43 (3): 366-373. 
Safko L, Brake DK. The social media bible. Tactics, tools \& strategies for business success. Hoboken, NJ: Wiley \& Sons; 2009.

Salzer-Mörling M, Strannegård L. Silence of the brands. European Journal of Marketing 2004; 38 (1/2): 224-238.

Schau HJ, Gilly MC. We are what we post? Self-presentation in personal web space. Journal of Consumer Research 2003; 30 (3): 385-404.

Schau HJ, Muniz AM, Arnould EJ. How brand community practices create value. Journal of Marketing 2009; 73 (5): 30-51.

Schroll R, Hemetsberger A, Füller J. Fine feathers make fine birds - community brands and branded communities. In: Dahl DW, Johar GV, van Osselaer SMJ, editors. Advances in Consumer Research, Vol. 38. Duluth, MN: 2011.

Simmons G. Marketing to postmodern consumers: introducing the internet chameleon. European Journal of Marketing 2008; 42 (3/4): 299-310.

Smith P, Zook Z. Marketing Communications, Integrating Offline and Online with Social Media, $5^{\text {th }}$ ed, London, UK: Kogan Page; 2011.

Smith T. Profit from the booming domain of social media. Campaign, UK: 2008, 25 July. p. 19.

Tepper M. The rise of social software. netWorker magazine 2003; September: 19-23.

Thompson CJ, Rindfleisch A, Arsel Z. Emotional branding and the strategic value of the Doppelgänger brand image. Journal of Marketing 2006; 70 (January): 50-64.

Tilly C. Democracy. Cambridge, UK: Cambridge University Press; 2007.

Torraco RJ. Writing integrative literature reviews: guidelines and examples. Human Resource Development Review 2005; 4 (3): 356-367.

Turner F. Where the counterculture met the new economy. The WELL and the origins of virtual community. Technology and Culture 2005; 46 (July): 485-512. 
Tuten TL. Advertising 2.0. Social Media Marketing in a Web 2.0 World. Westport, CT: Praeger; 2008.

Valenzuela S, Park N, Kee KF. Lessons from Facebook: the effect of social network sites on college students' social capital. Paper submitted to the 9th International Symposium on Online Journalism. Austin, Texas; 2008, 4-5 April.

http://online.journalism.utexas.edu/2008/papers/Valenzuela.pdf [10 November 2009].

Verona G, Prandelli E. A dynamic model of customer loyalty to sustain competitive advantage on the web. European Management Journal 2002; 20 (3): 299-309.

Watson T. Elders and newbies of the intertubes, I salute you. 2009, 13 February. http://www.tomwatson.co.uk/2009/02/elders-and-newbies-of-the-intertubes-i-salute-you/ [31 August 2009]

Webb J, Burgoyne B. You've got a friend: measuring the value of brand friending on social networks. Market Research Society, Annual Conference; 2009. http://www.warc.com/ArticleCenter/Default.asp?CType=A\&AID=WORDSEARCH89147\& $\mathrm{Tab}=\mathrm{A}[30$ April 2009]

Weber L. Marketing to the social web: how digital customer communities build your business. Hoboken, NJ: Wiley; 2007.

Wellman B, Quan Haase A, Witte J, Hampton K. Does the internet increase, decrease, or supplement social capital? American Behavioral Scientist 2001; 45 (3): 436-455.

Williams D. On and off the 'net: scales for social capital in an online era. Journal of ComputerMediated Communication 2006; 11 (2), article 11. http://jcmc.indiana.edu/vol11/issue2/williams.html [01 November 2009]

Zwick D, Bonsu SK, Darmody A. Putting Consumers to Work: “Co-creation” and New Marketing Govern-mentality. Journal of Consumer Culture 2008; 8 (2): 163-196. 